\title{
Distinguishing Financially Healthy From Unhealthy SMEs in China
}

\author{
YIN Piao-yang \\ Huaiyin Institute of Technology, Huai’an, China \\ Kanitsorn Terdpaopong \\ Rangsit University, Patumthani, Thailand
}

\begin{abstract}
This paper presents empirical evidence on the financial characteristics of Chinese entrepreneurial SMEs, both state-owned and private enterprises, listed in the Chinese stock markets during 2006-2009. Building on extant literature and using a parametric approach on 359 sample SMEs for 2006-2009 period, the study examines the financial characteristics that are embedded in the financially healthy and unhealthy Chinese SMEs. The findings of the study suggest that financially healthy Chinese SMEs have strength in terms of liquidity, profitability, and leverage ratios as compared to financially unhealthy SMEs with the exception of a few cases in leverage and profitability. These findings are worth noting to understand the uniqueness of financial characteristics of the Chinese SMEs and useful for policy makers to deal with the issues related to financially distressed SMEs in China.
\end{abstract}

Keywords: financial characteristics, Chinese SMEs, healthy and unhealthy SMEs

\section{Introduction}

SMEs' (small- and medium- sized enterprises) existence and contribution are predominant in most of the economies across the globe in both developed and emerging countries. Economic activities of vast majority of SMEs flow towards big enterprises and other sectors of the economy. It is perceived that no economy can sustain without a vibrant SMEs to reinforce social well-being and equity. The support of financially healthy SMEs is seem to be indispensable more for emerging countries like China than industrialized ones. This motivates conducting the study on the uniqueness of SMEs of the world's fastest growing emerging economy-China.

China has achieved great success in the economic development over the past three decades. The report of National Bureau of Statistics 2011 cited that the GDP had reached an average of 8\% in 2008, 9.2\% in 2009 plus a further increase to $10.3 \%$ in 2010 (Chinadaily, 2011). With the start of China's reforms in late 1970s, SMEs in China has begun to flourish, as symbolized by the booming township and village enterprises (TVEs) in rural areas. After nearly three decades of development, the number of SMEs in China amounted to 22 million (China Labor Statistical Yearbook, 2005), and the share of SMEs in the total number of enterprises was 99.3\% in 2004 (Yu, 2007). Moreover, since 2006 China has become the international hub in attracting both foreign

YIN Piao-yang, Master, Lecturer, Faculty of Economics and Management, Huaiyin Institute of Technology.

Kanitsorn Terdpaopong, Ph.D., Lecturer, Faculty of Accountancy, Rangsit University.

Correspondence concerning this article should be addressed to YIN Piao-yang, Huai'an, Jiangsu, 223001, China. E-mail: ypy1213@126.com. 
investments, both direct and portfolio, and currency reserves. In spite of these facts, the achievement was not reflected in the overall performance of the stock markets in Shanghai and Shenzhen. There has been a sharp fall in 2001 within these markets that led many businesses to collapse for numerous reasons. With the introduction of the first Bankruptcy Law, which came into effect on November 1988, many companies, especially those non-listed companies declared either for liquidation or bankruptcy. Many researchers and other associated stakeholders, with academic rigor and insight, identified the underlying causes of the markets meltdown, such as, inadequate market transparency, poor government regulation, lack of sound and reliable models to support the assessment of a company's financial situation and identification of potential distress (Altman, Heine, Zhang, \& Yen, 2007). These obstacles have a major influence on all types of enterprises in China, whether they are large or small, private or state-owned enterprises (SOEs).

\section{Hypothesis Development}

In Chinese context, SMEs include state-owned SMEs, urban concentration SMEs, township enterprises, private and individual enterprises. Majority of the SMEs are non-state-owned. SMEs in China are involved in many major economic sectors: industry (including manufacturing, mining, electricity, production and supply of fuel gas and domestic water), construction, transportation, the postal service, wholesale and retail sales, lodging and catering. These are classified as small or medium enterprises in terms of sales and/or the amount of total assets as well as the number of employees. The classification criteria can be seen in Table 1.

Table 1

Size Classification of Chinese SMEs

\begin{tabular}{|c|c|c|c|c|}
\hline Sector & $\begin{array}{l}\text { Employment } \\
\text { (people) }\end{array}$ & $\begin{array}{l}\text { Sales } \\
\text { (million RMB) }\end{array}$ & $\begin{array}{l}\text { Total assets } \\
\text { (million RMB) }\end{array}$ & Description \\
\hline Industry & $300-2,000$ & $30-300$ & $40-400$ & \multirow{2}{*}{$\begin{array}{l}\text { The medium enterprise has to reach minimum of the } \\
\text { three indices; otherwise classified as small firm. }\end{array}$} \\
\hline Construction & $600-3,000$ & $30-300$ & $40-400$ & \\
\hline Wholesale & $100-200$ & $30-300$ & \multirow[t]{5}{*}{ no requirement } & \multirow{5}{*}{$\begin{array}{l}\text { The medium enterprise has to reach minimum of the } \\
\text { two indices; otherwise classified as small firm. }\end{array}$} \\
\hline Retail & $100-500$ & $10-150$ & & \\
\hline Transportation & $500-3,000$ & $30-300$ & & \\
\hline Postal service & $400-1,000$ & $30-300$ & & \\
\hline Lodging and catering & $400-800$ & $30-150$ & & \\
\hline
\end{tabular}

Note. Source: Adapted from Temporary Regulations of Standards for SMEs in China (State Economic and Trade Commision, 2003).

In this study a financially healthy SME refers to a firm that has no distressed qualities or criteria such as, bond default, bank loan default, delisting of a company, government intervention via special financing, the filing for bankruptcy and liquidation. Therefore, a firm that does not possess these qualities can then be classified as a financially non-distressed firm. In this study, the financially healthy qualities of a firm also include the presence of positive operating cash flow and profit at the time the sample was taken. The 769 financial statements such as Balance Sheets, Comprehensive Income, and Statement of Cash Flow of the companies listed on the Shenzhen Stock Exchange between 2006-2009 that had showed healthy qualities were to be used as samples of financially non-distressed/healthy SMEs. Similarly, the companies that had defaulted on bonds and loans, had sought financial aid through government intervention and showed negative operating cash flow and low profit margins were used to represent the financially stressed/unhealthy firms. Of the SMEs that possessed these qualities on the Chinese Stock Markets a total 188 financial statements were then collected and used in this study. Thus, by categorizing the ratios into liquidity, leverage and profitability ratios, the main hypothesis of the study is adopted 
as: "There are significant differences in the financial ratios of healthy and unhealthy Chinese SMEs".

Based on this, the related sub-hypotheses can be applied to the SMEs in China:

$\mathrm{H}_{1}$ : The liquidity of the financially healthy Chinese SMEs is higher than that of unhealthy SMEs.

$\mathrm{H}_{2}$ : The leverage of the healthy Chinese SMEs is less than that of unhealthy SMEs.

$\mathrm{H}_{3}$ : The profitability of the healthy Chinese SMEs is higher than that of unhealthy SMEs.

\section{Research Methodology}

The study focuses on the small- and medium- sized enterprises (SMEs) as listed on the China SMEs Listed Boards in Shenzhen stock exchange. The total number of companies listed on the SME board on 3 March 2011 was 564 . Out of the total numbers, 359 companies were selected as the sample of the study utilizing the secondary available on-line resources, such as publically published financial statements. The sample comprises about 64 percent of total SMEs listed board in Shenzhen, which seems quite representative. A total of 957 financial statements of the selected China SMEs were collected from 2006-2009 (4 years) and were used to determine the differences between financially unhealthy SMEs' and healthy firms as represented on the Shenzhen Stock Exchange. This research employed parametric (Dependent and Independent Paired Sample T-Test) approach in the Statistical Package for the Social Sciences (SPSS) program in the process of data analysis. The validity of the study was limited to the reliability of the financial ratios collected from on-line financial statements of the listed SMEs. The study employed an analysis of numerous financial ratios that were able to differentiate financially unhealthy firms from healthy firms, using three significance levels $0.05,0.01$, and 0.001 .

Table 2

Variable Definition

\begin{tabular}{|l|l|l|l|}
\hline No. & Ratios & Names & Definitions \\
\hline
\end{tabular}

Liquidity measures: Liquidity refers to how quickly and cheaply an asset can be converted into cash or in other words the ability of current assets to meet current liabilities when due.

\begin{tabular}{|l|l|l|l|}
\hline 1 & CACL & Current assets to current liability ratio (Unit: Time) & $\begin{array}{l}\text { The amount of cash, account receivables, bills, inventory } \\
\text { and other current assets divided by current liability }\end{array}$ \\
\hline 2 & WCTA & Working capital to total assets ratio (Unit: Per cent) & $\begin{array}{l}\text { The current assets less current liability as a percentage of } \\
\text { total assets }\end{array}$ \\
\hline 3 & CFCL & Cash flow to current liability ratio (Unit: Per cent) & The net total cash flow as a percentage of current liability \\
\hline
\end{tabular}
Leverage measures: Leverage, also known as gearing or levering, refers to the use of debt to supplement investment or the degree to which a business is utilizing borrowed money.

\begin{tabular}{|l|l|l|l|}
\hline 4 & LLTA & $\begin{array}{l}\text { Long-term liability to total assets ratio (Unit: Per } \\
\text { cent) }\end{array}$ & $\begin{array}{l}\text { The amount of long-term liabilities as a percentage of } \\
\text { total assets }\end{array}$ \\
\hline 5 & TLTA & Total liability to total assets ratio (Unit: Per cent) & $\begin{array}{l}\text { The amount of short-term and long-term liabilities as a } \\
\text { percentage of total assets }\end{array}$ \\
\hline 6 & de & Debt to equity ratio (Unit: Time) & The amount of debt divided by equity \\
\hline Profitability measures: Profitability refers to an ability of a firm to generate net income on a consistent basis. \\
\hline 7 & TITA & Total income to total assets ratio (Unit: Per cent) & $\begin{array}{l}\text { The amount of total core and other income as a } \\
\text { percentage of total assets }\end{array}$ \\
\hline 8 & INTEBIT & $\begin{array}{l}\text { Interest expense to earnings before interest and tax } \\
\text { ratio (Unit: Per cent) }\end{array}$ & $\begin{array}{l}\text { The amount of interest expenses as a percentage of } \\
\text { earnings before interest and tax expenses }\end{array}$ \\
\hline 9 & EBITTA & $\begin{array}{l}\text { Earnings before interest and tax expenses to total } \\
\text { assets ratio (Unit: Per cent) }\end{array}$ & $\begin{array}{l}\text { All earnings before interest and tax expenses as a } \\
\text { percentage of total assets }\end{array}$ \\
\hline 10 & EAITTA & $\begin{array}{l}\text { Earnings after interest and tax expenses to total } \\
\text { assets ratio (Unit: Per cent) }\end{array}$ \\
$\begin{array}{l}\text { All earnings after interest and tax expenses as a } \\
\text { percentage of total assets }\end{array}$ \\
\hline
\end{tabular}

These two different groups of SMEs, i.e., healthy (769) and unhealthy (188) samples are making a total of 957 sets of financial statements. As defined in Table 2, a total of 10 independent variables were selected based 
on: (1) the most commonly used in previous studies; and (2) the availability of the data. These variables were divided into three categories according to the set hypotheses.

\section{Results and Discussions}

To start with some basic characteristics of the sample companies, it is observed that there is a mixture of ownership types. While the majority of $79 \%$ (283 companies) SMEs are private enterprises, the remaining $21 \%$ (76 companies) being state-owned enterprises (SOEs). Again, the majority of these SMEs (90\%) have been established between 6-20 years. Specifically, 55\% companies have been established between 6-10 years time and $36 \%$ between $11-20$ years.

The study divides the 10 ratios of healthy and unhealthy firms into three categories for both groups. Means of the three liquidity and four profitability ratios of healthy firms show higher liquidity and profitability than that of unhealthy firms, while unhealthy firms show higher leverage than that of healthy firms. Even though the cash flow to current liability ratio (CFCL) of healthy firms shows higher liquidity (healthy firms 66.94, and unhealthy firms 12.59) but with higher standard deviation (SD. 289.97) the test of inferential statistic is needed, the case of total income to total assets ratio (TITA) was likewise (SD. 78.53).

Table 3

Comparative Mean, Standard Deviation and T-test Summary Results

\begin{tabular}{|c|c|c|c|c|c|c|}
\hline \multirow[t]{2}{*}{ Variables } & \multicolumn{2}{|c|}{ Mean } & \multicolumn{2}{|c|}{ Std. Deviation } & \multicolumn{2}{|c|}{ T-Test } \\
\hline & Healthy & Unhealthy & Healthy & Unhealthy & Sig. & $t$ \\
\hline \multicolumn{7}{|c|}{ Liquidity: Healthy SMEs > Unhealthy SMEs } \\
\hline CACL (Time) & 3.03 & 1.93 & 4.44 & 1.48 & $0.000^{* * *}$ & 5.682 \\
\hline WCTA (\%) & 28.54 & 23.28 & 24.95 & 27.43 & $0.011^{*}$ & 2.539 \\
\hline CFCL (\%) & 66.94 & 12.59 & 289.97 & 69.77 & $0.000^{* * *}$ & 4.674 \\
\hline \multicolumn{7}{|c|}{ Leverage: Healthy SMEs < Unhealthy SMEs } \\
\hline LLTA (\%) & 4.56 & 5.08 & 7.78 & 9.88 & $0.438 \mathrm{NS}$ & -0.776 \\
\hline TLTA (\%) & 37.38 & 47.59 & 21.20 & 18.04 & $0.000^{* * *}$ & -6.025 \\
\hline DE (Time) & 0.77 & 2.13 & 0.77 & 14.91 & $0.215 \mathrm{NS}$ & -1.244 \\
\hline \multicolumn{7}{|c|}{ Profitability: Healthy SMEs > Unhealthy SMEs } \\
\hline TITA (\%) & 82.14 & 78.12 & 78.53 & 48.80 & $0.503 \mathrm{NS}$ & 0.670 \\
\hline INTEBIT (\%) & 13.32 & -8.17 & 21.85 & 359.24 & $0.413 \mathrm{NS}$ & 0.820 \\
\hline EBITTA (\%) & 10.44 & 4.87 & 17.97 & 10.46 & $0.000^{* * *}$ & 4.082 \\
\hline EAITTA (\%) & 7.52 & 2.27 & 5.49 & 7.93 & $0.000^{* * *}$ & 8.577 \\
\hline
\end{tabular}

Notes. ${ }^{* * *}$ Significant at $0.1 \%$ level $(0.001) ;{ }^{*}$ Significant at $5 \%$ level $(0.05)$; NS: Not significant.

The study aims to examine the uniqueness of financially healthy and unhealthy SMEs in China and to identify whether there is any significant difference between them in terms of the selected financial variables by using a parametric method (independent sample $T$-test).

Liquidity: In Table 3 on the column $T$-test, it is documented that financially healthy firms had liquidity ratios significantly higher as compared to that of unhealthy firms when taking into account the resulting calculated ratio means of CACL (current assets to current liability), WCTA (working capital to total assets) and CFCL (cash flow to current liability). The results on parametric $T$-test showed statistical significance on CACL ratio $t\left(\mathrm{df}^{1} 955\right)=5.862, p<0.001$; on WCTA ratio $t(955)=2.539, p<0.05$; and on CFCL ratio $t(955)=$

\footnotetext{
${ }^{1}$ Degree of freedom represented by combining the number of samples minus one of each group (a sum of 769 minus 1 and 188 minus 1) and this definition of the degree of freedom is used throughout the paper where the degree of freedom is shown.
} 
4.674, $p<0.001$. It is noted that unhealthy firms possessed higher current assets when compared to that of healthy firms with the net cash flow being over $60 \%$ of current liabilities. Yet, CACL and CFCL variables showed significantly strong differences between the two groups align with the WCTA variable showed weakly significant difference. These findings provide a general sense that liquidity ratios of financial healthy SMEs are superior to that of financially unhealthy SMEs. Thus, the first hypothesis is fully accepted.

Leverage: In regards to leverage ratios, LLTA (long-term liability to total assets) ratio did not show a significant difference between the two groups where parametric $T$-test provided the same result of the non-significance. This may be because of the main use of the short-term liability rather than of long-term one. The ratio of CLTA (current liability to total assets) amounted to $32.82 \%$ and $42.51 \%$, respectively for the healthy and unhealthy SMEs. However, when compared with TLTA (total liability to total assets) ratio, a significant difference is evident between the healthy and unhealthy. The results on parametric $T$-test showed statistical significance on TLTA ratio $t(955)=-6.025, p<0.001$. Again, the mean result of the DE (debt to equity) ratio did not show a significant difference between the two groups. Therefore, the second hypothesis is partially accepted.

Profitability: Unlike liquidity ratios, the profitability ratios showed mixed results regarding significant differences between the healthy and unhealthy SMEs. Both TITA (total income to total assets) and INTEBIT (interest expense to earnings before interest and tax ratio) ratios failed to reveal any significant difference between the two groups, even though means of the two groups seem to show the difference. However, the high standard deviation of 359.24 of unhealthy firms demonstrates that means of unhealthy firms were scattered. On the other hand, the profitability differences between both groups of SMEs can still be observed through the EBITTA (Earnings before interest and tax expenses to total assets) and EAITTA (Earnings after interest and tax expenses to total assets) ratios, EBITTA ratio $t(955)=4.082, p<0.001$, and EAITTA ratio $t(955)=8.577, p<$ 0.001 . Thus, the third hypothesis is partially accepted.

The findings provide an insight regarding financial characteristics of both healthy and unhealthy SMEs and lead to the conclusion that liquidity and profitability of the financially healthy enterprises, or the healthy SMEs were greater when compared to the financially stressed enterprises or the unhealthy SMEs. On the contrary, the unhealthy firms had higher liability, especially current liability, than that of healthy firms. With the non-significance result of TITA and INTTA ratios, it is considered that both healthy and unhealthy firms had similar ratios of total income and interest expense when compared with total assets. This is also in line with the LLTA and DE ratios where no statistical significance was found. This brings to the conclusion that the funding resource of both groups came from the combination of their own funding (equity) with other funds being raised through short-term liability generated from creditors, suppliers and loans from banking institutions. Although these firms were listed on the stock exchange to raise funds for capital investment from the open market, direct financing still remains a big challenge for most of the SMEs. Given the condition of listed SMEs, it is harder to evaluate the difficulties that unlisted SMEs generally confront to meet their financing need.

The results also support the conclusion that the unhealthy firms faced difficulties in several areas of business such as the cost of manufacturing goods, distribution costs and the final cost to the consumer, as well as the internal administrative and general expenses (the significant difference of EBITTA ratio). Both groups have to deal with high taxation costs due to the significance of the EAITTA ratio, in particular during the global economic crisis when the costs of export were higher than usual. When taxation costs and fees account for $20 \%$ of the total business costs including tax incentives for SMEs (Zhou, Guo, \& Lu, 2010), the simple solution 
would appear to be the lowering of tax rates and increased tax relief, yet this requires the support of the relevant organizations such as government departments and commercial banking institutions.

\section{Conclusion}

The differences of the financial ratios between the two groups are tested and confirmed. Both leverage and profitability ratios show partial distinctiveness between financially healthy and unhealthy SMEs. This result is beyond expectation for the financially healthy companies' tabling a better financial performance when compared with the financially unhealthy companies. Yet this is not supported in every financial variables/ratios undertaken to test. Considering the internal financial structure of enterprises within both groups, it is found that the financially healthy firms have higher liquidity and profitability than that of the unhealthy firms, while the unhealthy firms have higher liability, especially current liability, than that of healthy firms. It is important to note that long-term liability to assets ratio (LLTA) of both non-financially distressed and financially distressed firms does not show significant difference, which implies that both groups do not greatly finance their business with long-term liability but with short-term liabilities and equity. Therefore, the significant statistical findings fail to support the main hypothesis completely rather partially.

This result contradicts the result of previous researchers such as of Davidson and Dutia (1991) who found distressed firms had high proportion of long-term liability. This might be a unique nature of Chinese enterprises that have a high tendency of self-financing of their business. Both healthy and unhealthy enterprises tended to obtain short-term rather than long-term liability. Yet, the current liability and equity facilitated financially stressed SMEs to continue business operations with a degree of profitability. In other countries unhealthy firms would normally possess a high proportion of both long-term liability to total assets ratio (for example; the ratio may be over 100 percent of total assets such as in the case of Thai distressed SMEs) and total liability to total assets ratio (over 300 percent of total assets in the case of Thai distressed SMEs (Terdpaopong, 2009; Terdpaopong \& Mihret, 2011). Interestingly this is not the case in China. The results enable to conceive the distinguishing financial characteristics and differences between healthy and unhealthy SMEs in China in terms of the percentage of long-term liability to total asset, thus making obvious the unique financial characteristics of Chinese SMEs.

This study has some limitations in terms of numbers and types of independent variables. All of the variables are financial ratios, which were derived from financial statements of the samples firms. However, the wide range of variables including non-financial data such as age of business, education of business owners or managers, change of auditors, and other qualitative details of business managers, number of years established could assist the researchers to effectively detect the signs of a financial problem. There are a number of areas that require further academic focus, such as the establishment of a clear and concise definition of financially distressed SMEs used in academic research, including the identification of the causes of failure and other difficulties faced by SMEs, the detection of the indicators of potential future failure and the development of sophisticated econometric models for predicting potential failures.

\section{References}

Altman, E. I., Heine, M. L., Zhang, L., \& Yen, J. (2007). Corporate financial distress diagnosis in China. New York: New York University.

China Labor Statistical Yearbook. (2005). Beijing: China Statistics Press.

Chinadaily. (2011). China economy by numbers. China Daily. Retrieved January 21, 2011, from 
http://www.chinadaily.com.cn/business/2011/01/21/content_11894561.htm

Davidson, W. N., \& Dutia, D. (1991). Debt, liquidity and profitability problems in small firms. Entrepreneurship: Theory and Practice, 16(1), 53-64.

State Economic and Trade Commision. (2003). The state development planning commission.

Terdpaopong, K. (2009). How financially distressed SMEs could be distinguished from the successful ones in Thailand's market. Paper presented at the AGSE, Adelaide, Australia, 3-6 February, 2009.

Terdpaopong, K., \& Mihret, D. G. (2011). Modelling SME credit resk: A Thai empirical evidence. Small Enterprise Research Journal, 18(1), 63-79.

Yu, J. (2007). SME development and poverty reduction: Case study of Xiji county, China. Retrieved 15 January, 2011, from http://www.cfed.org/assets/pdfs/CHEDS.pdf

Zhou, J., Guo, T., \& Lu, S. (2010). SME law and policy analysis. Journal of US-China Publich Administration, 7(5), 79-82. 